\title{
Analysis on the Development and Revolution of Modern Sichuan
}

\section{Opera Accompaniment Music}

\author{
Shengdong Yue ${ }^{1, a}$, Long Qiang ${ }^{2, b}$ \\ ${ }^{1}$ School of Music of Chengdu Normal College \\ a7892383@qq.com
}

Key words: Modern Sichuan opera, Accompaniment music, Development, Revolution

\begin{abstract}
This paper takes brief analysis on the historical revolution of modern Sichuan opera, respectively takes discussion on the history development of percussion music and orchestral music in 'Hard and soft scene'and 'Up and down hand system'of Sichuan opera,takes conclusion on Sichuan percussion music's characteristics of from big to small and from simple to complex,besides, takes preliminary discussion on the origin of 'Surnay Qupai(the names of the tunes to which qu are composed)'and 'Melodica Qupai'in Sichuan opera orchestral music and on the reason of the formation of mixed music providing accompany for Sichuan opera.
\end{abstract}

\section{Introduction}

Ministry of Education Humanities-Social Science Study Youth Fund Project 'Formation, Development and Evolution Study of Modern Sichuan Opera', Project No. : 15YJC760123, Humanities and Social Sciences Key planning project of ' Development and Revolution of Sichuan Opera After New China ‘Opera Revolution’host by Education Office of Sichuan Province , Breeding project of Chengdu Normal University 'Formation, Development and Evolution Study of Modern Sichuan Opera’, Project No. : CS14SD04.

Sichuan opera accompaniment music is also called 'Scene', and it is made up with percussion music and orchestral music, which is called 'hard scene' and 'soft scene'in proffession inner.'Hard scenes'is also called 'Percussion Instruments in Chinese Operas', referring to percussion instruments such as gongs and drums and the operator,the number of which is usually 5; 'Soft scene' includes Huqin, small Huqin, big tube, flute, surnay etc, which is usually operated in turn by two people.Because people did not pay great attention to the old-timey Sichuan opera, 'soft scene’becomes less prominent.

'Hard scene' generally consists of the following personnel and musical instruments: one drum-player beating a small drum, called as 'Drum-beating Artisan'and commonly known as 'Sitting-Controlling cammander'which means a unified command; The four musicians in 'Down hand system'must control at least 10 musical instruments, the man playing big gong should also be able to play night time-indicating gong, bag gong, Chinese gong chimes etc, and this man is called 'Big Gong-knocking Artisan'; The man playing top Cymbal should be able to play Su gong(a kind of gong); The man playing Tupan(a kind of drum) should be able to play Sujiao(a Chinese musical instrument) and Clapper Opera, and this man is called 'Tupan-playing Artisan'; The man playing smalle gong should be able to paly horse gong and 'Dang Dang'(a kind of gong), and this man is called 'Small gong-playing Artisan'. Playing 10 kinds of musical instruments by 5 persons form the percussion music in Sichuan opera. The proportion of percussion music in old-timey Sichuan opera 
is big, and some saying like, 'one stage of gong and drum and half stage of opera', 'three percentage of singing and seven percentage of beating'etc, which vividly illustrates the position and function of percussion music in Sichuan opera. Besides, in Sichuan opera, the 'Drum-beating man' is the leader of the whole 'scene', who is the commander of 'soft and hard scene' and the general director of the accompaniment music for Sichuan opera.

Percussion music of Sichuan opera mainly originates from Sichuan folk music 'DuanGong gong and drum' and 'Yangko drum and gong', which has the characteristics of rough and very melodious sound,sonorous and lively rhythm. The old-timey witch drama, DuanGong drama, festive activity, lantern drama, playing drums and gongs, etc.such folk art all had influence on the formation and development of percussion music of Sichuan opera, besides, from the composition, timbre, 'Gong and Drum Scriptures' and personnel condition engaged in this work in old time, we can know the origin relations in it. The show of old-timey Sichuan opera is presented in the form of square, and the shape,structure and size is much bigger than that in modern time, according to the recalls of old actor of Sichuan opera, the diameter of big gong nears to two feet, weight about 15 and $16 \mathrm{~kg}$ and the sound of it is loud and clear, besides, big cymbals weighs 2.5 kilograms, and the diameter of Tupan is up over $40 \mathrm{~cm}$, and the size of horse gong, small gong, and Jiaozi(one Chinese musical instrument) are larger than that now.Because the performance place at that time mainly are temple or hall or outdoor area, which is not 'sound-gethered', it sounds not 'deafening'.

From Qing dynasty to the republic of China(1912-1949), the old habit and custom of each theatrical troupe is to beat gong and drum on stage to attract audience before the drama starts, which has 3 parts of procedures, so it is called 'Three Chui and Three Beating'(Chui is one method of playing musical instrument, such as surnay). "Beating Tuo'(Tuo refers to the shell of one Chinese animal and it can be used as one musical instrument ) is the collective calling of Three Chui and Three Beating', which is divided into the following three steps: first is 'Drum Beating', namely Tupan solo(Tupan is a kind of drum used in Chinese operas ); Second is the play of 'Tuo', namely Tuo-made gong and drum playing under the command of Tupan; Finally is the mixed play of surnay and gong and drum, after all the steps, then the performance will begin formally.1 Gong and drum play on stage has the function of attracting audience to watch, urging people to the theatre and suppressing the spot noise, and it has the characteristics of long play time, difficult skills, large quantity of Qupai, which is the most representative link of accompaniment music in traditional Sichuan opera. After 1949, almost all the Sichuan opera came into the theatre in city, and the form of 'gong and drum play on the stage' has gradually disappeared, up to now, many Qupai and performing forms have been lost.

For the percussion music in Peking Opera, Kunqu, PingJu etc., apart from Tupan, then are a large gong and a pair of cymbals, which is often called 'Three Pieces of Copper'. Besides, their weight are lighter, and the sound of gongs and cymbals is 'Kang Qior Kang Qior.percussion music in Sichuan opera has the calling of 'Four Pieces of Copper', that is, a Tupan, a large gong, a pair of big cymbals, a horse gong (This is the default configuration, if the scale is small, then change the big cymbals with hinge son and change horse gong to small gong).The weight of big gongs and big cymbals in Sichuan opera is heavy, so the sound of them is 'Dang Chew, Dang Chew', and Sichuan opera can be distinguished easily from the other opera only by the features of percussion timbre.

In the beginning of the 20th century, due to the increase in the number of building for play garden in city, and as the change of public appreciation habits and aesthetic temperament and interest, Sichuan opera artist began to make improvement in Sichuan opera percussion music,and made its size smaller and form lighter. Starting from the 1930 s, Sichuan opera artists with 
Drummer Shaowu Yu as representative, took transformation of the beating form for gong and drum, and gradually formed the performance skills with gorgeous and fluent characteristics and it was often called 'Flowery Gong and Drum'. To the 1950 s, with the decrease of the shape of gong and drum, the performance style of Dexterity and brisking had formed in Western Sichuan region, which is the 'Gong and drum in Upper dam' with Chengdu as the center.

In Sichuan opera, orchestral music of accompaniment music is called'soft scene', which corresponds to 'hard scene', the commonly known name of percussion music, which structure can be divided into wind music and string music.The main musical instruments of wind music are long and short bamboo flute (long bamboo flute is called 'Qu flute'(Used for Kun Qu)in profession inner,short bamboo flute is called 'Bang flute'(used for Bangzi)in profession inner), large and small surnay (big surnay is called 'surnay'in profession inner, small surnay is called 'Ji Nazi'in profession inner), and Sheng(a reed pipe wind instrument) etc. other musical instruments; The main musical instruments of string music are all kinds of urheen and dulcimer, sanxian(a three-stringed plucked instrument), yueqin(a four-stringed plucked instrument with a full-moon-shaped sound box), pipa (a plucked string instrument with a fretted fingerboard) etc. The 'soft scene'in old-timey Sichuan opera has only one 'up accompanist'and on 'down accompanist', besides, the 'up accompanist', as the lead, master the musical instruments for key musical accompaniment of each opera tune, and the 'down accompanist', in the time of accompanying, beating 'Jiaozi' and 'Bangzi'in high-pitched tune opera at the same time. Totally, the number of the personnel in accompaniment band is seven for the traditional Sichuan opera.

The main musical instruments of wind music in Sichuan opera are surnay and bamboo flute.Surnay Qupai mainly originated from kunqu opera, according to the narration of old actor Fuzhou Wei, the author of Sichuan Opera Surnay Qupai, that Surnay Qupai has music score and lyric, most of which belong to the lyrics of kunqu opera, and in old times, people used the method of oral teaching that inspires true understanding within for the development of Sichuan opera, which made a lot of things lost and also changed the original form of many things.For the use of Qupai in past, most of them have its certain features, express certain feelings, and have certain application field and rules.Before the period of emperor Guangxu in Qing dynasty, each Qupai has its homophony,and most of Qupai belong to the tone of Character 'Fan',however, the tune of 'Fan'has the character of hidden bitterness and darkness, and it is difficult to use, so in the period of emperor Guangxu in Qing dynasty,Xiaoshan Li and Fangshan $\mathrm{Hu}$ use the small melody as the fundamental key, which is welcomed by later learners, and then it gradually mixes with the original form.Actually, Surnay in Sichuan opera also absorbed the content of Sichuan folk music, blowing and percussion music in 'witch group',, religious music, music of popular narratives and brother opera music, and after long-term integration and development, it gradually forms the morphological characteristics of today.

Sichuan opera surnay has about more than 150 pieces, and it has two types of application forms, one is 'single' ( the independent existing Qupai) and 'court' (also known as 'court type of Qupai'), besides, the common stage application has nearly 30 pieces.For a long time, at the time of Sichuan opera surnay accompany for various tunes of Qupai,they also have formed many independent Qupai forms with strong expressive force.In terms of the performance for theater scene, the scene of welcoming and seeing off guests, marriage,funeral,charge forward,fighting scene military plays all have particular Qupai for each one. Besides, for the feeling expression, the feeling of pleasure, feeling of sadness, and feeling of meeting again after seperation etc. all also have particular Qupai for each one.There are also some specialized 'Qupai', which has strict application forms in traditional opera, such as 'Emperor song'for the coming of emperor on stage , 'Tablet'and 'Pin 
Gong'(one kind of opera)for the coming of immortal on stage. 'Court' is one Qupai form, and it refers to one group of Qupai with same tune, which exists in one drama or a series of dramas with strict stipulation for the application order. For example, the 'Qi Yan Hui 'in Chengtang Qupai concludes 'Dian Jiang' 'Qi Yan Hui' 'Yue Nen Hao' 'Red Embroidered Silk Shoe 'Wei Sha'( the seven are the name of each Qupai), besides, the built-up sequence of these Qupai cannot be upside-down.In traditional Sichuan opera, the use of the Surnay has certain specification, general it is mastered and used by drummer for the length,speed and developing of Qupai according to the needs of plot and characters.

Almost all the Surnay Qupai have the 'Set Play', the so-called'Set Play' refers to the mix of the 'blowing' of surnay and the 'beating' of gong and drum.Set play has two forms, one is the set play that drummer commands on the 'basin drum', the musical instruments of this set play are Jiaozi and flat pan gong with the rhythm of Qupai-beating and flowers;Another is the set play that drummer commands with the 'eye method' ( gestures) on small drum, and this set play has some 'gong and drum scriptures', the length of Qupai and speed of rhythm are mastered by drummer.

The main instruments of Sichuan opera string music is Huqin, including small urheen, erhu, pan-hu, Gai Banzi, fat tube etc. The commonly used pluck instruments are dulcimer, sanxian, moon Lute , pipa, etc.Small urheen is similar with the jinghu of Peking opera, called 'chuan hu' inline, which belongs to the main accompaniment musical instruments of Pi Huang Qiang, so Pi Huang Qiang of Sichuan opera is also called 'Huqin Qiang'by borrowing the reputation of it. Huqin drama in Sichuan opera premiere take small urheen as the main accompaniment instrument, in addition to that, it usually takes erhu music as accompaniment music . Cover board is the main instrument of 'Bangzi' cavity, by which reputation the Bangzi cavity in Sichuan opera is also called 'cover board',besides, it has been called 'Bounce'(general term for Chinese opera melodies other than Kunshan and Yiyang melodies)in old time because of the origination from the Chuan Bangzi of Qin cavity, so the Bangzi cavity in Sichuan opera is also called 'Bounce drama'. The 'bounce drama' in Sichuan opera,in addition to takes cover board as the main accompaniment instrument, it often accompanied by pan-hu, erhu, and matched with the harp, three-stringed, moon lute, etc. The erhu used in Sichuan opera commonly is erhu with alto voice, commonly known as 'sichuan erhu', which is not only used as the accompaniment of kunqu opera, high-pitched tune, urheen and bounce drama etc., but also used with the 'fat tube' as the main accompaniment musical instrument of laten drama in Sichuan opera.Sichuan opera occasionally use the erhu with high pitch and low pitch, but generally seldom use big erhu.The string instrument in Sichuan opera is not only used for the cavity accompaniment of various tunes, also used for the rendering environment atmosphere, reflecting the emotional state in music passages.

The general term of bamboo flute and various instrument is 'Piano Flute Melody', which is used to refer to all kinds of 'interlude music', and it is used in the five tunes of Sichuan opera.In general, the Qupai with flute as the musical instrument in Sichuan opera is called 'Flute music', and the Qupai with flat and small urheen as the main musical instruments is called ' lyra music', besides, some Qupai can be palyed by flute or cover board or urheen, such as 'Crying for Emperor' 'Small-opened Door'etc.There are three kinds of sources for the lyra and flute music score in Sichuan opera. One origination is Kunqu opera, and same with the Qupai of surnay, many Qupai of lyra and flute have music score and lyrics, because of the long-time method of oral teaching that inspires true understanding within,we can find that the lirics forms of this two have big differences by comparing the lyrics of the existing and little number of Qupai and Kunqu opera, such as 'Little Peach Red' and 'East Mountain in Han'.The second origination is the borrowing of each opera drama from each other, such as 'Little-opened Door' and 'Mrs. Liu'etc. besides,we also can find the 
similar Qupai in Peking opera and other operas. The third origination is the absorbtion of folk music and Quyi music. The number of lyra and flute music score is above 150, and that of the commonly used on stage is above 30. These music scores are used as background music, in addition to that, part Qupai also have conventional meaning, such as the corrsponding Qupai in the scenes of wine banquet, dressing, weaving, garden sceneray appreciation, sermon and worship Budda. The application of lyra and flute music score also has some specifications,and some Qupai can only be used in a tune, and some can be used in more than two tunes, and rare can be used in five tunes.

For a long period, the accompaniment music of Sichuan opera use the 'soft and hard scene' and 'Up and down system'. After 1949, a large number of music workers began to contact with Sichuan opera music along with the 'Opera Reform', and they made design for new tune music and made reform exploration on traditional Sichuan opera, gradually the system of 7-person Sichuan opera accompanient music was broken. They added national instruments to accompaniment music, such as erhu, Chung-hu, Gao-hu, pipa, dulcimer etd., besides also added western instruments, such as the violin family, trumpet, clarinet, flute etc. In later half of the 20th century, with the carrying forward of this reform, Sichuan opera accompaniment music gradually formed several types of small scale of opera national orchestra, a hybrid music group with ethnic musical instruments as predominance and orchestra with mixed folk music and single pipe music, which types have been existing to today.

\section{References}

[1] Local Chronicles Compilation Committee of Chengdu.Chengdu City Magazine.Sichuan Opera Magazine[M]. Beijing:Local press,1997:121

[2] Xiangming Zeng,Distinctive Percussion Music in Sichuan Opera[N]. Chongqing Evening News,1997-4-11

[3] Chinese Operas Magazine Editorial Board.Chinese Operas Magazine.Sichuan Edition[M]. Beijing:China ISBN Center,1994:223

[4] Chinese Opera Music Integration Editorial board.Chinese Opera Music Integration.Sichuan Edition[M]. Beijing:China ISBN Center,1997:826-831 